\title{
Cutting Properties of Austenitic Stainless Steel by Using Laser Cutting Process without Assist Gas
}

\author{
Hitoshi Ozaki, Yosuke Koike, Hiroshi Kawakami, and Jippei Suzuki \\ Graduate School of Engineering, Mie University, 1577 Kurima-machiya, Tsu, Mie 514-8507, Japan \\ Correspondence should be addressed to Hitoshi Ozaki, ozaki@mach.mie-u.ac.jp \\ Received 27 April 2012; Revised 24 July 2012; Accepted 7 August 2012 \\ Academic Editor: Augusto Belendez
}

Copyright () 2012 Hitoshi Ozaki et al. This is an open access article distributed under the Creative Commons Attribution License, which permits unrestricted use, distribution, and reproduction in any medium, provided the original work is properly cited.

\begin{abstract}
Recently, laser cutting is used in many industries. Generally, in laser cutting of metallic materials, suitable assist gas and its nozzle are needed to remove the molten metal. However, because of the gas nozzle should be set closer to the surface of a workpiece, existence of the nozzle seems to prevent laser cutting from being used flexible. Therefore, the new cutting process, Assist Gas Free laser cutting or AGF laser cutting, has been developed. In this process, the pressure at the bottom side of a workpiece is reduced by a vacuum pump, and the molten metal can be removed by the air flow caused by the pressure difference between both sides of the specimen. In this study, cutting properties of austenitic stainless steel by using AGF laser cutting with $2 \mathrm{~kW} \mathrm{CO}_{2}$ laser were investigated. Laser power and cutting speed were varied in order to study the effect of these parameters on cutting properties. As a result, austenitic stainless steel could be cut with dross-free by AGF laser cutting. When laser power was $2.0 \mathrm{~kW}$, cutting speed could be increased up to $100 \mathrm{~mm} / \mathrm{s}$, and kerf width at specimen surface was $0.28 \mathrm{~mm}$.
\end{abstract}

\section{Introduction}

Laser cutting is one of the thermal cutting processes such as gas cutting and plasma cutting [1]. In laser cutting, as a focused laser beam melts or vapors a workpiece locally, it has the following features. First, width of cut kerf is narrower than that of the conventional cutting process. Second, laser cutting can achieve precision cut with small distortion. Therefore, laser cutting is applied in many industries such as automobile, aerospace, shipbuilding, and so on [2].

In laser cutting of metallic materials, molten metal is usually removed by using suitable assist gas at high pressure as shown in Figure 1 [3]. Thus, the special gas nozzle is needed to provide the assist gas such as oxygen, nitrogen, air, and so on. However, because of the gas nozzle should be moved closer to the position about $1 \mathrm{~mm}$ from the surface of a workpiece, it's thought that existence of the nozzle causes lack of flexibility of laser cutting. For example, when the laser cutting of odd-shapes material pressed into shapes is intended, the gas nozzle may touch the material. Additionally, in the remote laser cutting studied in these days [4-6], gas nozzle using itself is difficult. From this viewpoint, it's expected that the application range of laser cutting will expand by realizing without assist gas.

For this reason, the new cutting process, Assist Gas Free laser cutting, hereafter, called as AGF laser cutting, has been developed and investigated about cutting properties in our laboratory [7]. In this process, as shown in Figure 2, the pressure at the bottom side of a workpiece is reduced by a vacuum pump, and the molten metal can be removed by the air flow caused by the pressure difference between top and bottom sides of the specimen. In addition, the pressure difference is important for this process, since it corresponds to the assist gas pressure in conventional laser cutting process.

In the present study, cutting properties of austenitic stainless steel by using AGF laser cutting were investigated. At first, laser power and cutting speed were varied in order 


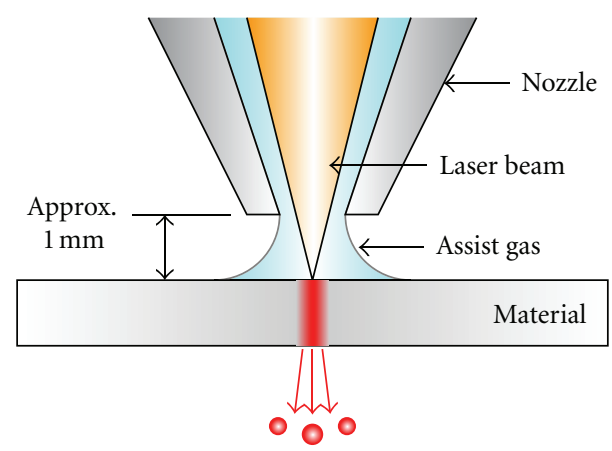

FIGURE 1: Schematic of conventional laser cutting process of metallic materials with assist gas.

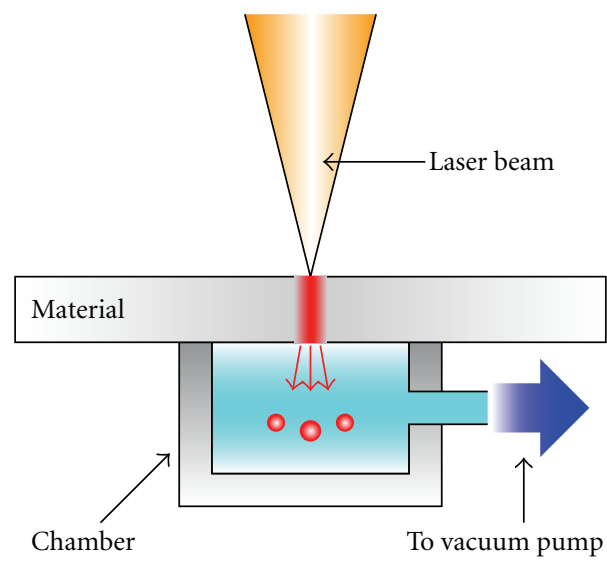

FIGURE 2: Schematic of Assist Gas Free laser cutting process.

to study the effect of these parameters on cutting properties. Moreover, effect of cutting condition on pressure in chamber during cutting process was discussed.

\section{Experimental Procedure}

2.1. Materials Used. As materials, austenitic stainless steel, JIS SUS304, was used for AGF laser cutting. Thickness of the SUS304 plate was $1 \mathrm{~mm}$ in this study. Width of the specimen was $39 \mathrm{~mm}$, and length was $300 \mathrm{~mm}$. Chemical compositions of the material used were shown in Table 1.

2.2. Procedure of AGF Laser Cutting Process. A schematic of AGF laser cutting equipment using a $2 \mathrm{~kW} \mathrm{CO}_{2}$ laser was shown in Figure 3.

A chamber connected to a vacuum pump was mounted on an NC work table. After a sheet material was set on top side of the chamber, the pressure in the chamber was reduced by the vacuum pump. When inside of the chamber became near vacuum state, AGF laser cutting experiment was carried out. Laser beam melts the material locally; the molten metal can be removed by the pressure difference between both sides of the sheet.

2.3. Process Parameters for AGF Laser Cutting. Process parameters for AGF laser cutting were shown in Table 2.
A $2 \mathrm{~kW} \mathrm{CO}_{2}$ laser of continuous wave with circular polarization was used. In this study, laser power was varied from 1.0 to $2.0 \mathrm{~kW}$. Focal length of lens was $127 \mathrm{~mm}$, and focal position was set at the surface of the SUS304 plate. Piercing time was $1 \mathrm{~s}$ every time. Cutting speed was varied from 10 to $110 \mathrm{~mm} / \mathrm{s}$. Shielding gas of nitrogen was used to protect the focusing lens. Cut length $100 \mathrm{~mm}$ was controlled by the NC program.

\section{Experimental Results and Discussions}

3.1. Process Window of AGF Laser Cutting. Process window of AGF laser cutting is shown in Figure 4.

The condition which could be cut with all length of $100 \mathrm{~mm}$ is shown as circles, and that which could not be cut is shown as crosses. When laser power was increased, the range of cutting speed which could be cut was expanded. This is because heat input to the SUS304 plate is augmented by the increment of laser power at higher cutting speeds.

From this result, critical cutting speed $V_{c}$ for each laser power was found and shown in Table 3.

$V_{c}$ was $50 \mathrm{~mm} / \mathrm{s}$ at laser power $1.0 \mathrm{~kW}$, and $100 \mathrm{~mm} / \mathrm{s}$ at $2.0 \mathrm{~kW}$. When laser power was increased, the critical cutting speed $V_{c}$ was also increased, since sufficient heating was applied to the material in spite of high cutting speed. Calculated heat input at the critical cutting speed with laser power of $1.0 \mathrm{~kW}$ is $20 \mathrm{~J} / \mathrm{mm}, 1.5 \mathrm{~kW}$ is $19 \mathrm{~J} / \mathrm{mm}$ and $2.0 \mathrm{~kW}$ is 


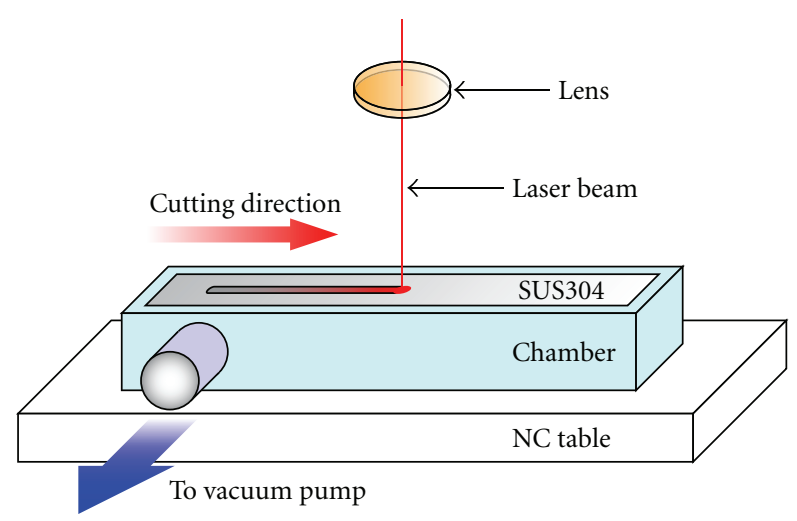

FIGURE 3: Schematic of AGF laser cutting equipment.

TABLE 1: Chemical compositions of JIS SUS304, standard value, mass $\%$.

\begin{tabular}{lcccccc}
\hline $\mathrm{C}$ & $\mathrm{Si}$ & $\mathrm{Mn}$ & $\mathrm{P}$ & $\mathrm{S}$ & $\mathrm{Ni}$ & $\mathrm{Cr}$ \\
\hline$\leqq 0.08$ & $\leqq 1.00$ & $\leqq 2.00$ & $\leqq 0.045$ & $\leqq 0.030$ & $8.00 \sim 10.50$ & $18.00 \sim 20.00$ \\
\hline
\end{tabular}

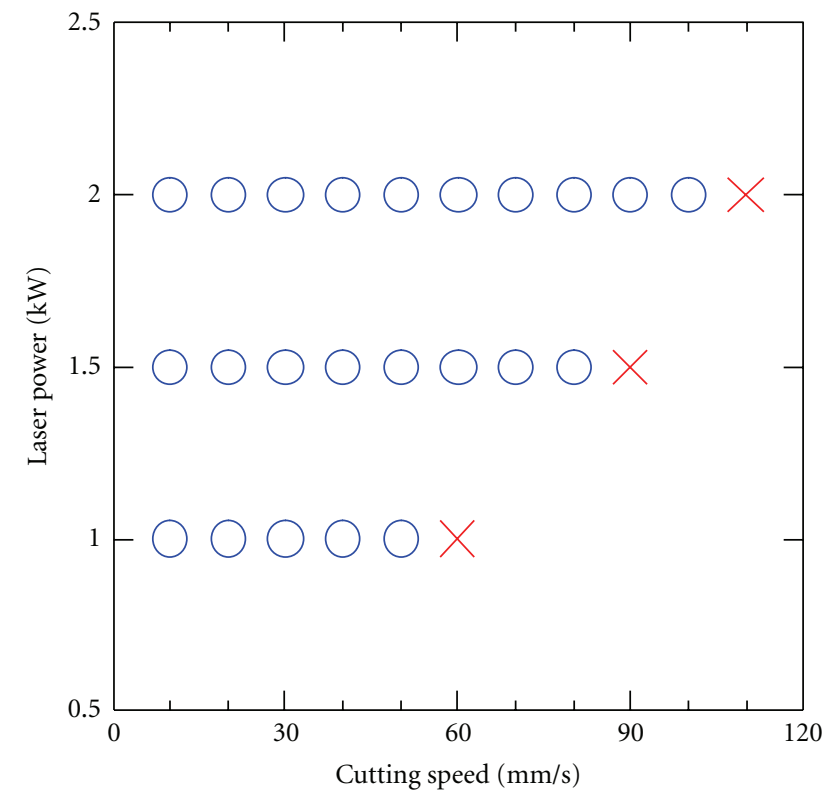

Possible

Х Impossible

FIGURE 4: Process window of AGF laser cutting with different laser power and cutting speed.

$20 \mathrm{~J} / \mathrm{mm}$, respectively. Therefore, the heat input of $19 \mathrm{~J} / \mathrm{mm}$, is minimum required for AGF laser cutting of the SUS304 plate of $1 \mathrm{~mm}$ thickness.

3.2. Cross-Sectional Shapes of Kerf. Macro cross-section of kerf with laser power of $1.0 \mathrm{~kW}$ and cutting speed of $50 \mathrm{~mm} / \mathrm{s}$ is shown in Figure 5.

Cut kerf was formed and seen at the center of the picture. In order to discuss cross-sectional shapes of kerf, its profiles were measured with all cut specimens. The cross-sectional

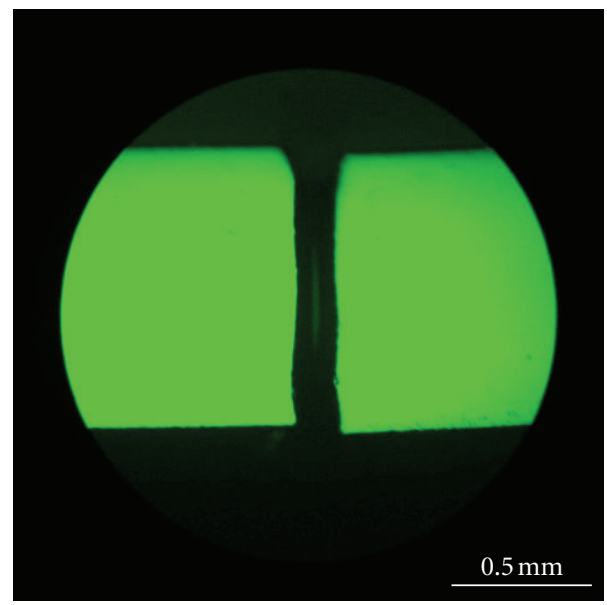

FIGURE 5: Macro cross-section of specimen after AGF laser cutting with laser power of $1.0 \mathrm{~kW}$ and cutting speed of $50 \mathrm{~mm} / \mathrm{s}$.

TABle 2: Process parameters for AGF laser cutting.

\begin{tabular}{lc}
\hline Laser type & $\mathrm{CO}_{2}$ laser $(\mathrm{CW})$ \\
Polarization of laser & Circular polarization \\
Laser power & $1.0 \sim 2.0 \mathrm{~kW}$ \\
Focal length of lens & $127 \mathrm{~mm}$ \\
Defocused distance & $\pm 0 \mathrm{~mm}$ \\
Piercing time & $1 \mathrm{~s}$ \\
Cutting speed & $10 \sim 110 \mathrm{~mm} / \mathrm{s}$ \\
Shielding gas & $\mathrm{N}_{2}: 15 \mathrm{~L} / \mathrm{min}$ \\
Cut length & $100 \mathrm{~mm}$ \\
\hline
\end{tabular}

shapes of kerf at different laser power and cutting speed are shown in Figure 6.

In this figure, the upper side is corresponded to the laser irradiated surface in each graph. In all cutting conditions, cut kerfs are formed perpendicular to the surface of the plate. 


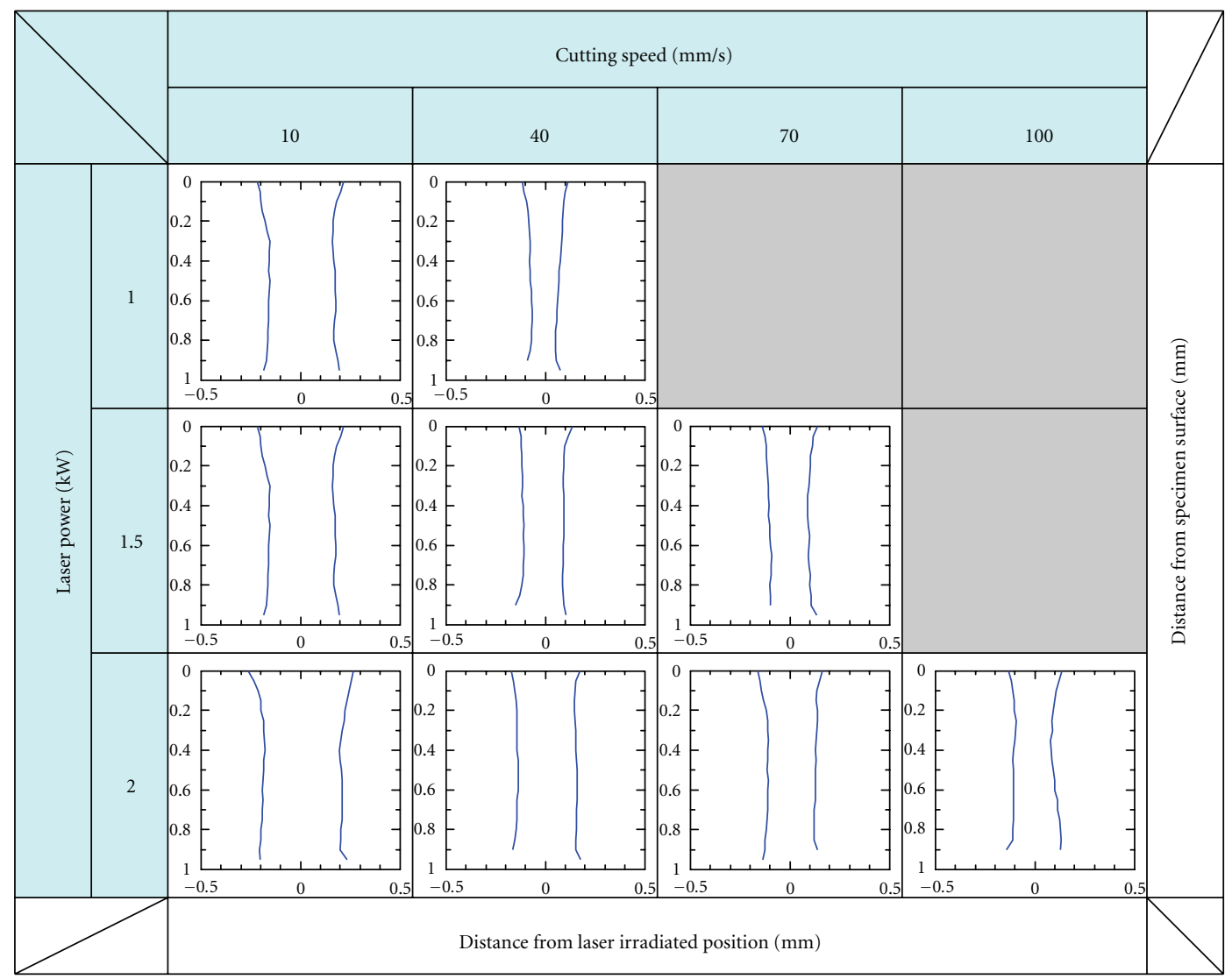

FIgURE 6: Cross-sectional shapes of kerf at different laser power and cutting speed.

TABLE 3: Critical cutting speed $V_{c}$ of AGF laser cutting for each laser power.

\begin{tabular}{lc}
\hline Laser power & $V_{c}$ \\
\hline $1.0 \mathrm{~kW}$ & $50 \mathrm{~mm} / \mathrm{s}$ \\
$1.5 \mathrm{~kW}$ & $80 \mathrm{~mm} / \mathrm{s}$ \\
$2.0 \mathrm{~kW}$ & $100 \mathrm{~mm} / \mathrm{s}$ \\
\hline
\end{tabular}

Furthermore, the kerf shapes are almost the same though laser power or cutting speed is varied. These facts were confirmed by measuring kerf taper. In this study, the taper was defined as one-half of the difference between upper and lower width of kerf, as mentioned in the literature [3].

Figure 7 shows the effect of cutting speed on kerf taper at different laser power. Maximum of the taper was about $0.06 \mathrm{~mm}$ at laser power $2.0 \mathrm{~kW}$ and cutting speed $10 \mathrm{~mm} / \mathrm{s}$. Hence, it was found that formation of the taper was suppressed, because of the taper was below $0.06 \mathrm{~mm}$ in all cutting conditions.

However, as shown in Figure 6, kerf width and area are different depending on the cutting condition. Therefore, they are quantitatively evaluated in the following section.

3.3. The Effect of Cutting Speed on Kerf Width. Figure 8 shows the effect of cutting speed on kerf width at different laser power. The width was measured at the specimen surface of the laser irradiated side.

At same cutting speed, when laser power was increased, kerf width was also increased, since the heat input was augmented. By contrast, when cutting speed was increased, kerf width was decreased, as the heat input was also decreased. Maximum kerf width was $0.56 \mathrm{~mm}$ at laser power $2.0 \mathrm{~kW}$ and cutting speed $10 \mathrm{~mm} / \mathrm{s}$. Minimum was $0.25 \mathrm{~mm}$ at laser power $1.0 \mathrm{~kW}$ and cutting speed $50 \mathrm{~mm} / \mathrm{s}$.

\subsection{The Effect of Cutting Speed on Removed Area of Kerf.} Likewise, Figure 9 shows the effect of cutting speed on removed area of kerf. The removed area of kerf means the cross-sectional area of kerf.

At same cutting speed, when laser power was increased, removed area of kerf was also increased. By contrast, when cutting speed was increased, removed area of kerf was decreased. As mentioned above, this is because the influence of increasing and decreasing of the heat input. Maximum removed kerf area was $0.37 \mathrm{~mm}^{2}$ at laser power $2.0 \mathrm{~kW}$ and cutting speed $10 \mathrm{~mm} / \mathrm{s}$. Minimum was $0.11 \mathrm{~mm}^{2}$ at laser power $1.0 \mathrm{~kW}$ and cutting speed $50 \mathrm{~mm} / \mathrm{s}$.

3.5. The Effect of Heat Input on Kerf Shapes. Laser power and cutting speed can be treated as one parameter of the heat input. Thus, the kerf width and the removed area of 


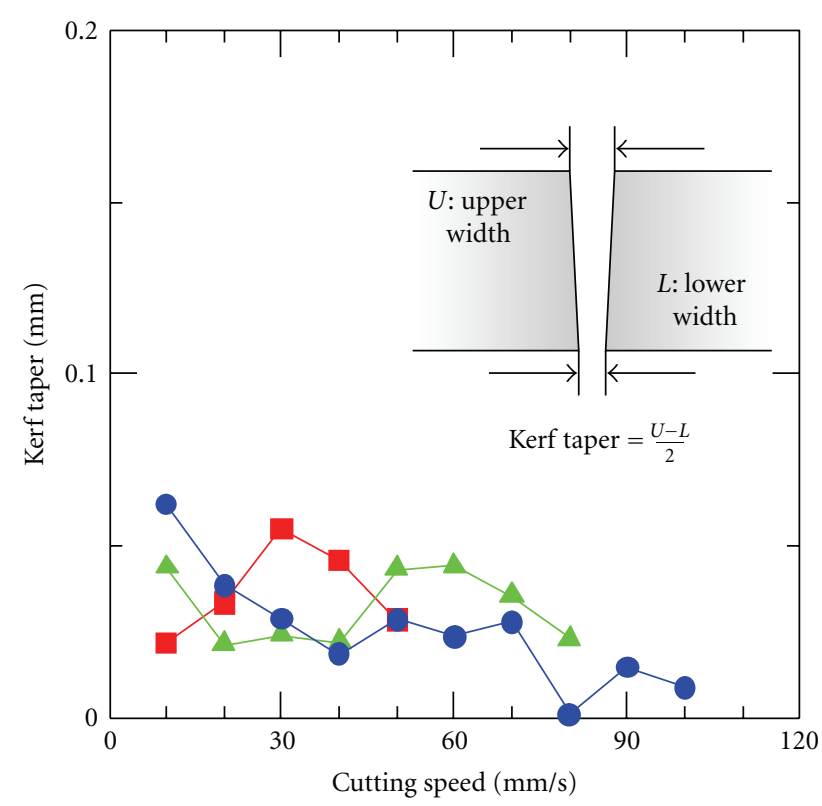

Laser power:

$-2 \mathrm{~kW}$

$\triangle 1.5 \mathrm{~kW}$

$-1 \mathrm{~kW}$

Figure 7: Effect of cutting speed on kerf taper at different laser power.

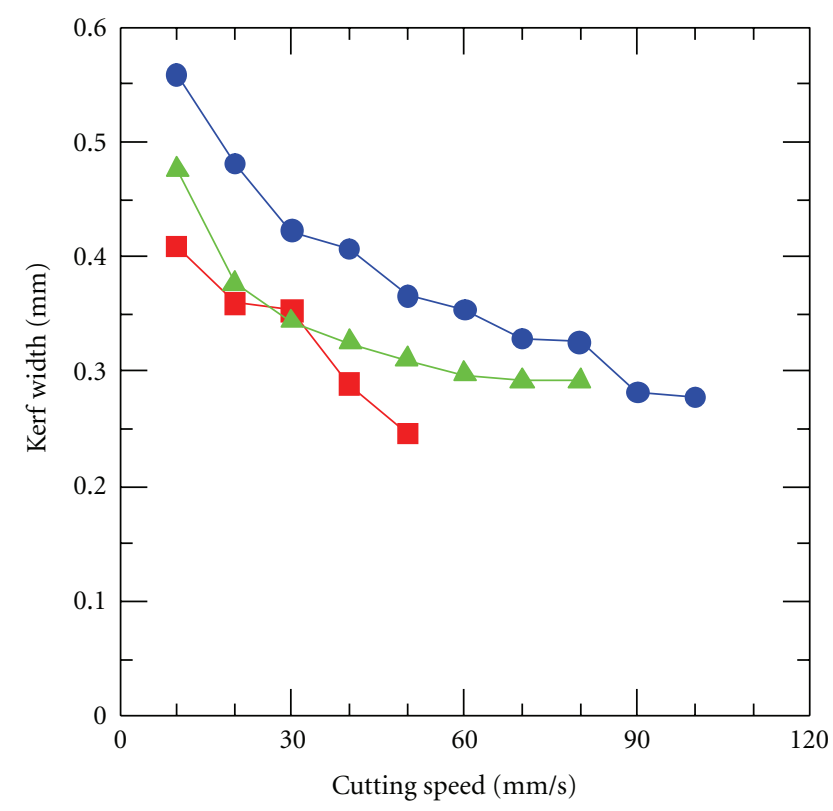

Laser power:

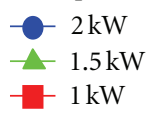

FIGURE 8: Effect of cutting speed on kerf width at different laser power.
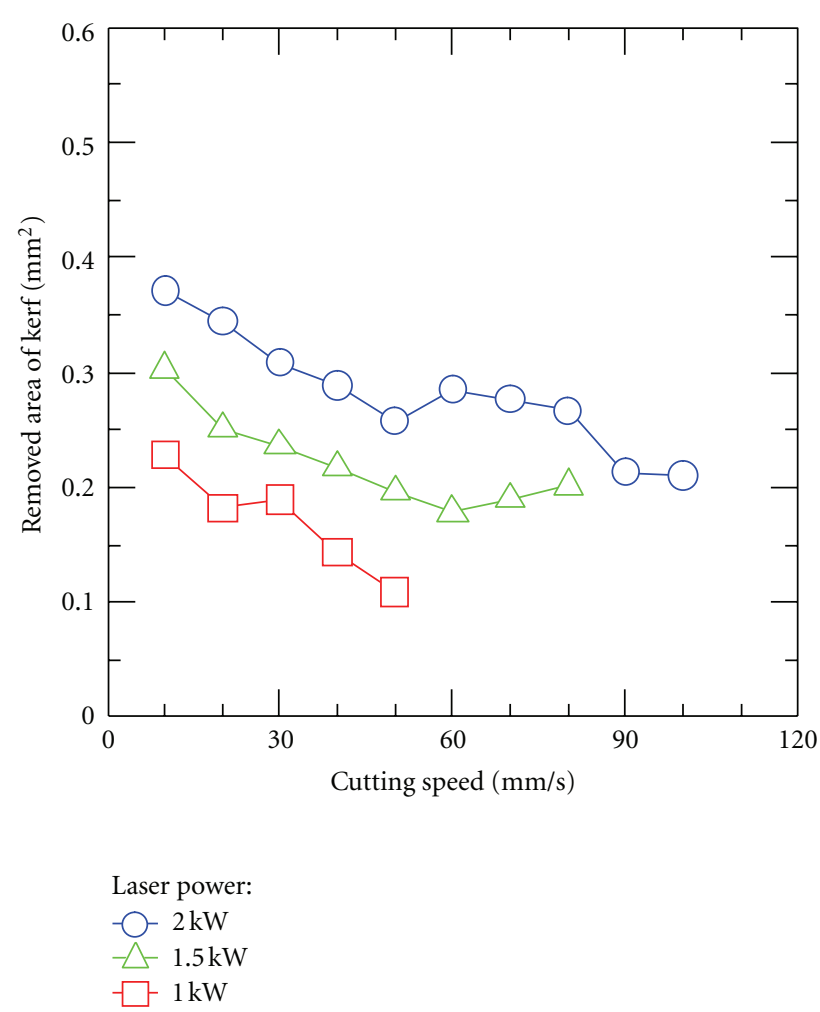

FIGURE 9: Effect of cutting speed on removed area of kerf at different laser power.

kerf were organized by the heat input. Figure 10 shows the effect of the heat input on kerf shapes. Figure 10(a) shows the relationship between the heat input and the kerf width at the specimen surface, and Figure 10(b) shows the heat input and the removed area of kerf.

When heat input was increased, both kerf width and removed kerf area were also increased. As shown in Figure 10(a), the kerf width is roughly corresponding at the low heat input. In contrast, the kerf width of $2.0 \mathrm{~kW}$ laser power is wider than that of the other laser powers at the high heat input. Beam transverse mode of the $\mathrm{CO}_{2}$ laser used is $\mathrm{TEM}_{00}$ under the laser power of $1.0 \mathrm{~kW}$, after that, the mode turns into $\mathrm{TEM}_{01}^{*}$ as increment of the laser power. Hence, it's considered that the kerf width was affected by the laser beam mode.

As shown in Figure 10(b), the removed area of kerf is different in three laser powers regardless of the same heat input. This is because the various kerf shapes were present as shown in Figure 6. At the low laser power like $1.0 \mathrm{~kW}$, the kerf shape was near inverted trapezoid. When the laser power increased, the kerf shape became rectangle, since the lower part of the plate was heated well.

3.6. Appearance of Cut Surface. In order to evaluate cutting quality, the appearance of cut surface was observed. Figure 11 shows the appearance of cut surface at different laser power and cutting speed. 


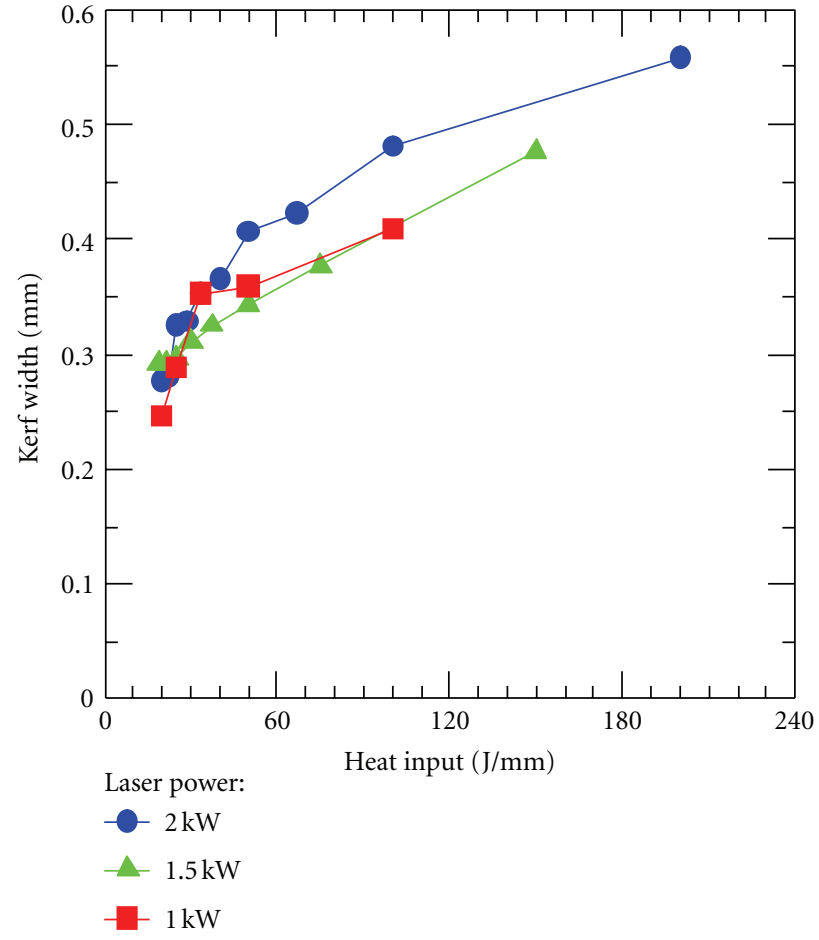

(a) Kerf width

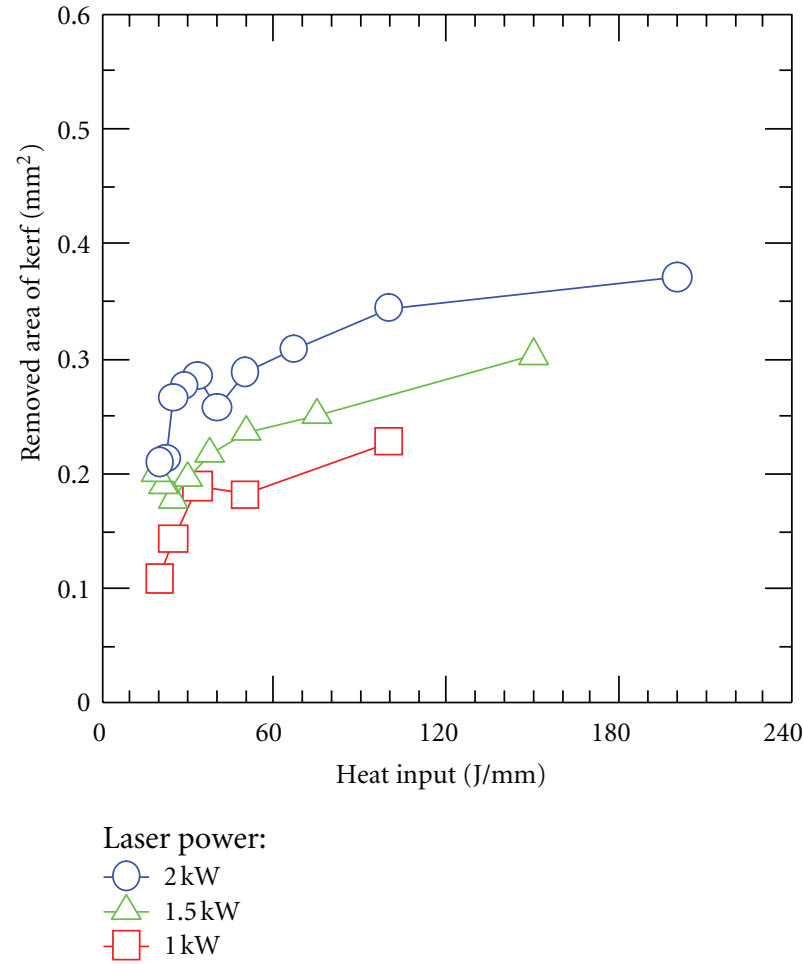

(b) Removed area of Kerf

Figure 10: Effect of heat input on kerf shapes.

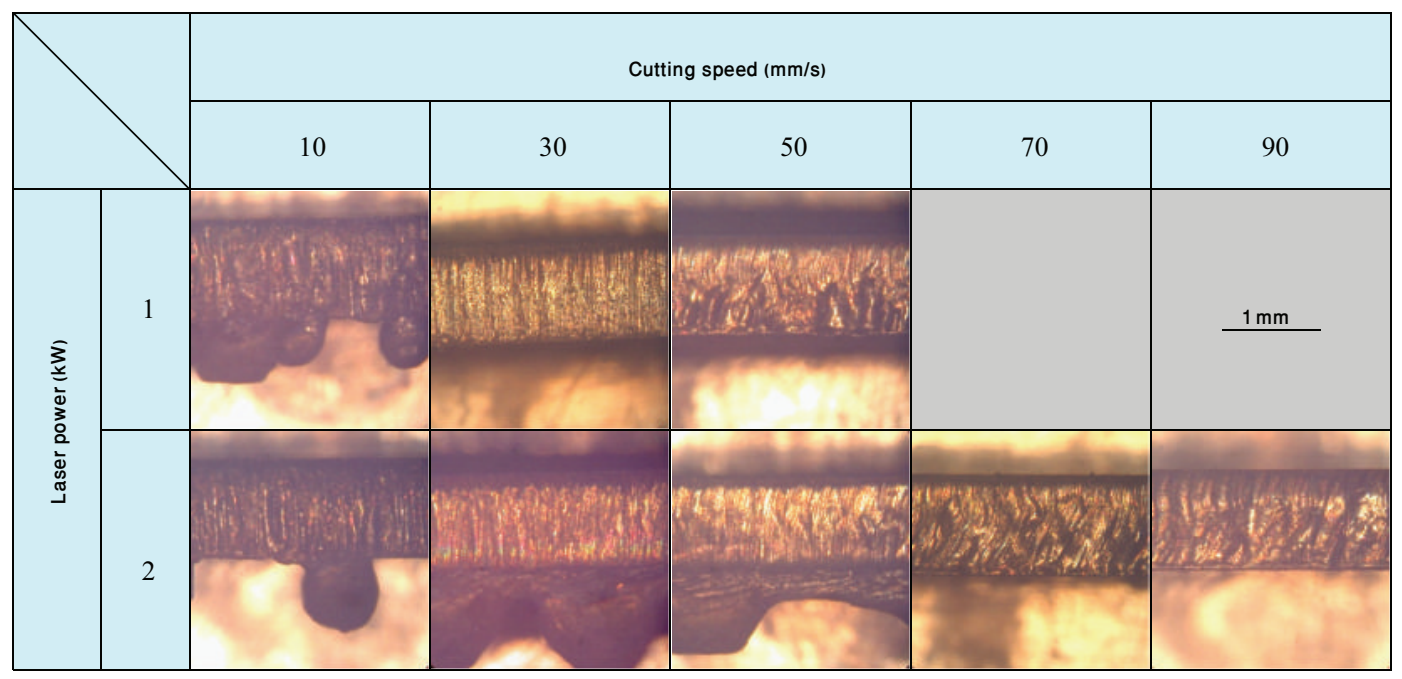

FIGURE 11: Appearance of cut surface at different laser power and cutting speed.

With low cutting speed such as $10 \mathrm{~mm} / \mathrm{s}$, the formation of dross was confirmed. When cutting speed was decreased, because the amount of the molten metal was increased, part of the molten metal was not removed from the kerf and remained at the bottom surface of the plate as the dross. However, when cutting speed was increased, drossfree cutting was achieved. In the high cutting speed, since the amount of molten metal is few, the metal was ejected smoothly. Therefore, it's thought that high-speed cutting is effective in dross-free cutting. 


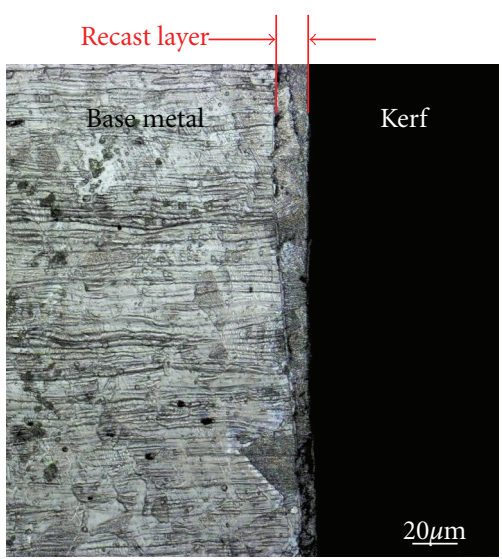

Figure 12: Microstructure of cut surface with laser power of $2.0 \mathrm{~kW}$ and cutting speed of $100 \mathrm{~mm} / \mathrm{s}$.

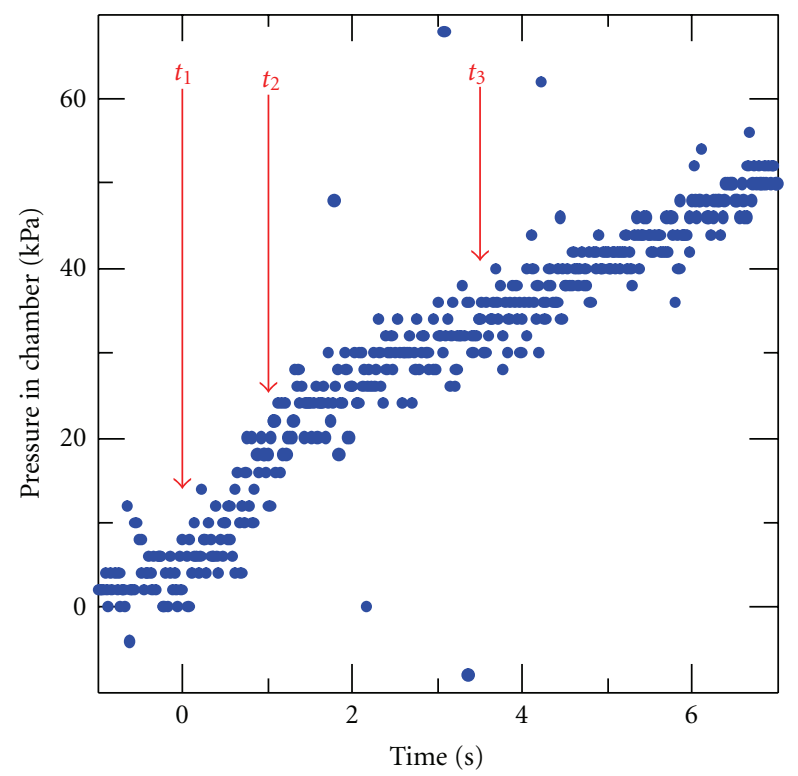

FIGURE 13: Change of pressure in chamber during AGF laser cutting with laser power of $2.0 \mathrm{~kW}$ and cutting speed of $40 \mathrm{~mm} / \mathrm{s}$.

In addition, cut surface was observed in detail after etching the kerf cross-section with hydrochloric acid. Figure 12 shows microstructure of the cut surface near the center of the plate thickness with laser power of $2.0 \mathrm{~kW}$ and cutting speed of $100 \mathrm{~mm} / \mathrm{s}$.

An approximately $10 \mu \mathrm{m}$ thin layer of different microstructure from the base metal was observed on the cut surface. This layer may be formed by solidification of the molten metal which wasn't removed, that is, recast layer. Similar thin layer was also confirmed at other cutting conditions.

\subsection{Effect of Cutting Condition on Pressure in Chamber} during AGF Laser Cutting. As mentioned above, in AGF laser cutting, the molten metal can be removed by the air flow caused by the pressure difference between both sides of the

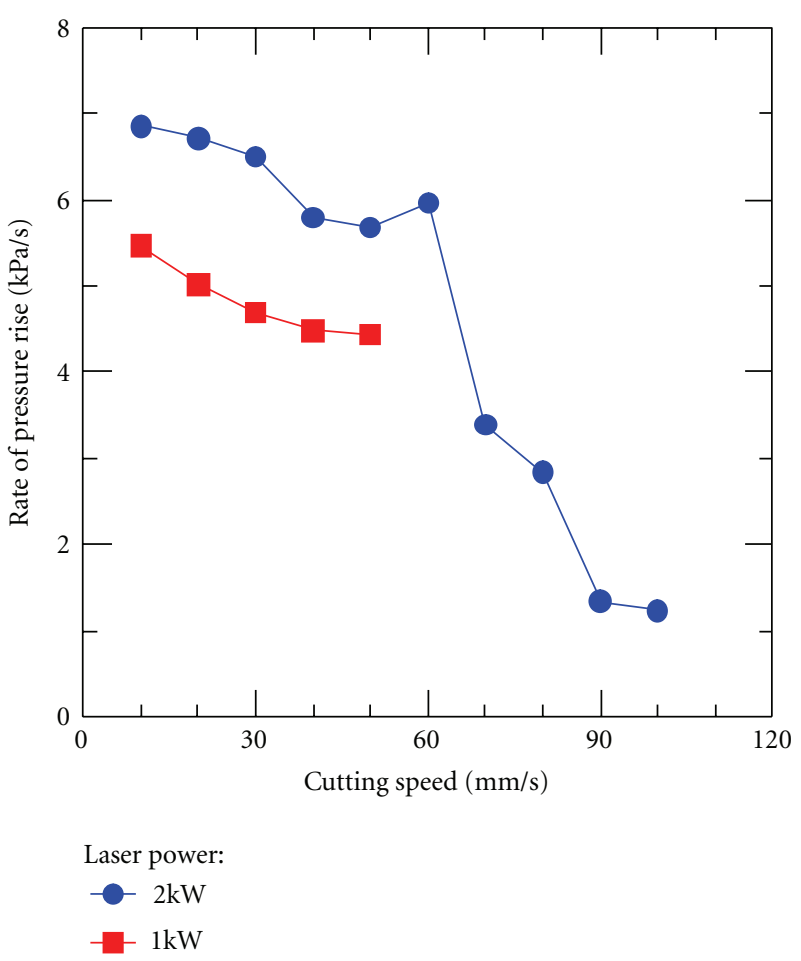

FIGURE 14: Effect of cutting speed on rate of pressure rise during AGF laser cutting at different laser power.

specimen. However, as cutting progresses, air flows into the chamber from the cut kerf. In other words, the pressure difference decreases. Thus, the pressure in the chamber was measured during cutting process by using a pressure sensor. As an example, the change of the pressure during AGF laser cutting with laser power of $2.0 \mathrm{~kW}$ and cutting speed of $40 \mathrm{~mm} / \mathrm{s}$ was shown in Figure 13, where, start time of piercing was defined as " $t_{1}$ ", start time of cutting as " $t_{2}$ ", and end time of cutting as " $t_{3}$." Before $t_{1}$, the pressure in the chamber was about $0 \mathrm{kPa}$, or near vacuum state. From $t_{1}$ to $t_{2}$, because of the piercing process had been undergone, the pressure rose. From $t_{2}$ to $t_{3}$, cutting process had been in progress, the pressure continued to increase for further inflow of atmosphere.

In order to discuss pressure change during AGF laser cutting process, between $t_{2}$ and $t_{3}$, it's defined as rate of pressure rise. The rate was calculated from the slope of the line obtained by least squares approximation from $t_{2}$ to $t_{3}$ in each cutting condition. Figure 14 shows the effect of cutting condition on the rate of pressure rise during AGF laser cutting at different laser power.

At same cutting speed, when laser power was increased, the rate of pressure rise was also increased, since the kerf width was expanded as shown in Figure 8. By contrast, when cutting speed was increased, the pressure rise rate was decreased, as the kerf width was also decreased as shown in Figure 8.

Therefore, AGF laser cutting by low heat input is desirable, because narrow kerf width and dross-free cutting can be obtained as above. In addition, since the rate of 
pressure rise during cutting is low, longer cutting length can be ensured under low-heat-input cutting.

\section{Conclusions}

The present study is focused on cutting properties of austenitic stainless steel by using AGF laser cutting process. The following conclusions can be drawn.

(1) Increase in the laser power led to increase of the critical cutting speed. With the laser power of $2.0 \mathrm{~kW}$, the critical cutting speed was $100 \mathrm{~mm} / \mathrm{s}$.

(2) The cross-sectional shapes of kerf were almost the same though the laser power or the cutting speed was varied. The kerf taper was below $0.06 \mathrm{~mm}$ in all cutting conditions.

(3) When the heat input was increased, the kerf width and the removed area of kerf were also increased.

(4) When the cutting speed was high, the dross-free cutting was achieved. The thin recast layer, about $10 \mu \mathrm{m}$, was observed on the cut surface.

(5) When the laser power was decreased or the cutting speed was increased, the rate of pressure rise in the chamber during cutting process was decreased.

\section{References}

[1] Japan Welding Society, New Edition Advanced Theory of Welding and Joining Technology, Sanpo Publications, 2011.

[2] T. Arai, M. Kutsuna, and I. Miyamoto, Laser Cutting Process, Machinist Publishing, 1994.

[3] M. Kanaoka, Practical Business of Laser Materials ProcessingVital Point of Work and Measure Against Trouble, Nikkan Kogyo Shimbun, 2007.

[4] M. F. Zaeh, J. Moesl, J. Musiol, and F. Oefele, "Material processing with remote technology-revolution or evolution?" Physics Procedia, vol. 5, pp. 19-33, 2010.

[5] J. Hatwig, G. Reinhart, and M. F. Zaeh, "Automated task planning for industrial robots and laser scanners for remote laser beam welding and cutting," Production Engineering, vol. 4, no. 4, pp. 327-332, 2010.

[6] H. Shamoto, T. Ikeda, and A. Tsuboi, "Development of remote cutting technology by high quality solid state laser," in Reports on The 406th Topical Meeting of The Laser Society of Japan, pp. $17-21,2010$.

[7] J. Suzuki, Japanese Patent Publication, 2007-190590. 

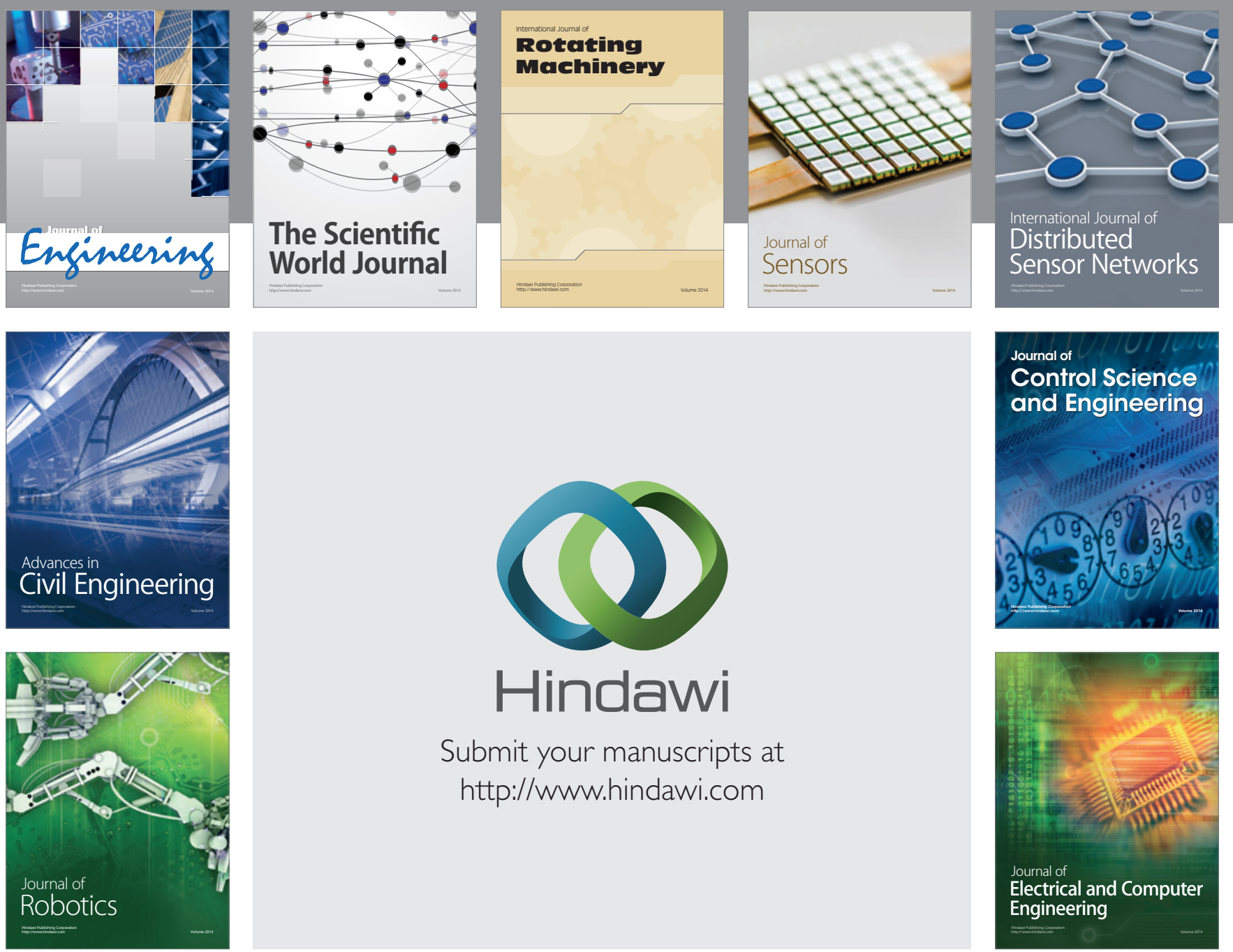

Submit your manuscripts at

http://www.hindawi.com
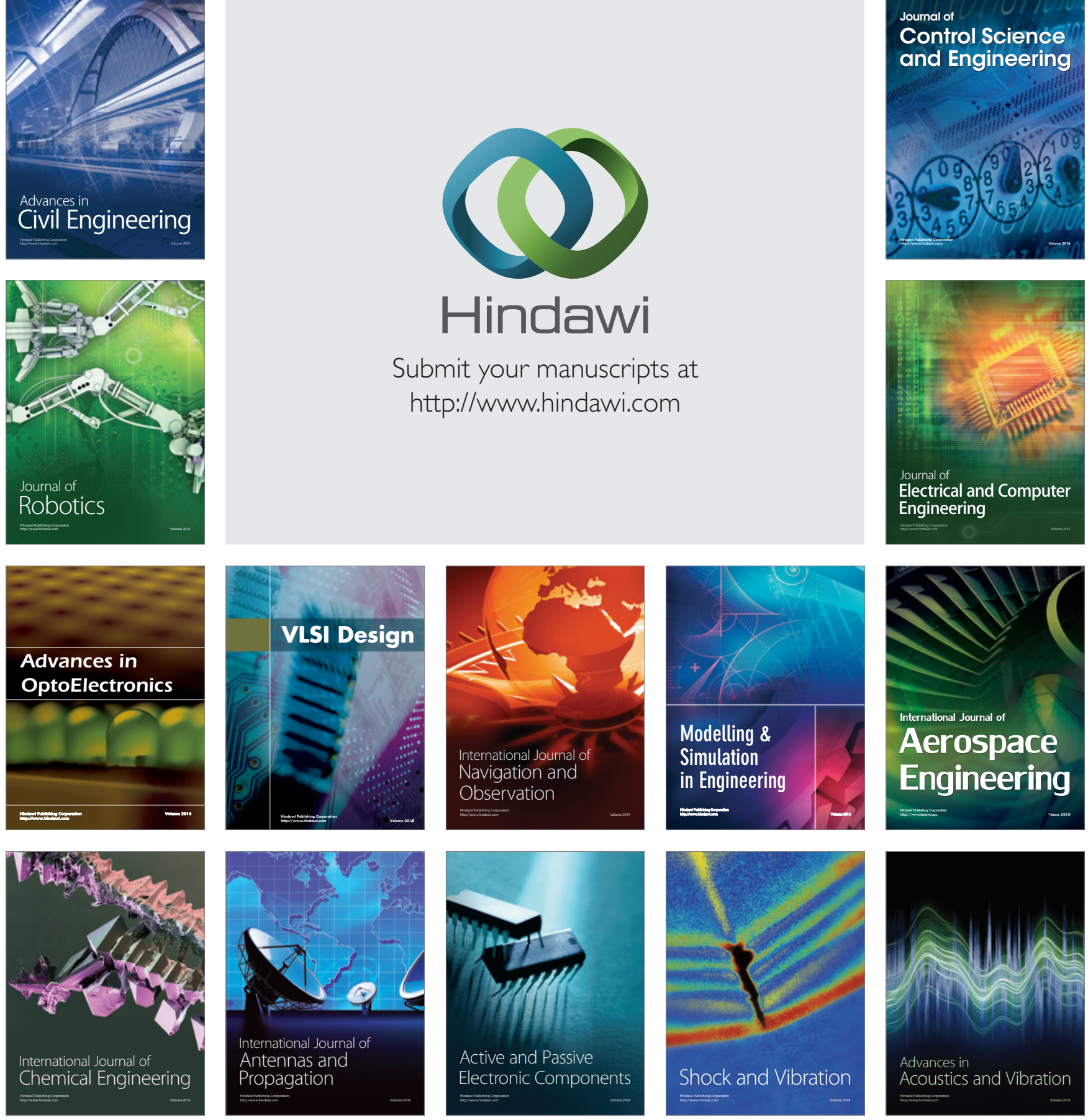